\title{
Rendimiento académico en la asignatura "Álgebra y Geometría Analítica" de FACENA-UNNE EN 2018
}

Esp. Liliana N. Caputo, Prof. María Laura Mosci, Mgter. Eduardo Porcel ${ }^{(*)}$

\section{RESUMEN}

La asignatura Algebra y Geometría Analítica de la Facultad de Ciencias Exactas y Naturales y Agrimensura de la Universidad Nacional del Nordeste, pertenece al plan de estudios de ocho de las carreras que conforman la oferta curricular de la mencionada Casa de Altos Estudios, a saber: Bioquímica, Licenciatura en Ciencias Físicas, Licenciatura en Ciencias Químicas, Ingeniería Eléctrica, Ingeniería en Agrimensura, Ingeniería en Electrónica, Profesorado en Ciencias Químicas y del Ambiente y Profesorado en Física.

La variedad de perfiles de formación que atraviesan a la asignatura, así como también el elevado número de alumnos que la cursan (ya que corresponde al primer cuatrimestre del primer año de estudios de las ocho carreras mencionadas), obligan a trabajar en numerosas comisiones de clases, tanto teóricas como prácticas, lo cual com- plejiza el proceso de seguimiento y evaluación de los procesos de enseñanza y aprendizaje durante el cursado de la asignatura. De ahí que el presente trabajo, tiene como objetivo realizar una detallada descripción de los resultados de dicho cursado en el año lectivo 2018, en las evaluaciones parciales que se realizan a fin de regularizar la asignatura, discriminados según la comisión de clases prácticas a la que cada estudiante asistió. Para realizar el análisis mencionado se utilizó la técnica de análisis de datos composicionales, presentándose los resultados obtenidos mediante gráficos ternarios. Asimismo, se determinó el porcentaje de desgranamiento de alumnos durante el cursado de la asignatura, llegando a la conclusión que sólo un 49\% de los alumnos inscriptos completan el curso y de éstos casi el $51 \%$ la regulariza. Mediante las envolventes convexas de las comisiones correspondientes a alumnos de Ingeniería y a las de es-

\footnotetext{
(9) Facultad de Ciencias Exactas y Naturales y Agrimensura - UNNE.

Contactos: proflcaputo@gmail.com; moscilaura@hotmail.com ; porcelfel@arnet.com.ar
} 
tudiantes de otras carreras, se comparó el rendimiento académico de la cursada de los dos grupos de comisiones, observándose que las Ingenierías ostentan un rendimiento académico ligeramente superior al resto de las carreras. Finalmente, se concluye que el elevado número de fracasos de los alumnos en el cursado de la asignatura está, principalmente, explicado por el desgranamiento y, a fin de paliar esta problemática y de favorecer la retención de los estudiantes, se proponen algunas modificaciones a las currículas de las carreras de Ingeniería.

PALABRAS CLAVES: Rendimiento Académico en Algebra - Desgranamiento - Estudiantes del Primer Año de Ingenierías - Datos composicionales.

\section{INTRODUCCION}

La asignatura Algebra y Geometría Analítica de la Facultad de Ciencias Exactas y Naturales y Agrimensura de la Universidad Nacional del Nordeste, pertenece al plan de estudios de ocho de las carreras que conforman la oferta curricular de la mencionada Casa de Altos Estudios, a saber: Bioquímica, Licenciatura en Ciencias Físicas, Licenciatura en Ciencias Químicas, Ingeniería Eléctrica, Ingeniería en Agrimensura, Ingeniería en Electrónica, Profesorado en Ciencias Químicas y del Ambiente y Profesorado en Física

Si bien las clases de la asignatura se dictan desde el año lectivo 2001 (por entonces, existía un mismo programa para todas las carreras y una carga horaria semanal de 8 horas reloj, distribuidas en 4 destinadas a clases prácticas y 4 a clases teóricas), a raíz de los procesos de acreditación de algunas carreras, las cargas horarias y contenidos mínimos correspondientes a cada carrera fueron modificados, en virtud de las sugerencias de CONEAU. Por tal motivo, desde 2016 rigen programas distintos, para adecuarse a las exigencias de las distintas $\mathrm{cu}^{-}$ rrículas.

En virtud de estas modificaciones, las cargas horarias son:

En las carreras de Ingeniería: 10 hs reloj semanales, distribuidas en 2 clases teóricas de 2 hs reloj de duración cada una y 3 clases prácticas, también de 2 hs. reloj cada una.

En Bioquímica y Licenciatura en Ciencias Químicas: 7.5 hs. reloj semanales, distribuidas en 1 clase teórica de $2 \mathrm{hs}, 1 \mathrm{cla}$ se teórica de 1.5 hs reloj de duración, más 2 clases prácticas de 2 hs reloj de duración cada una.

En las tres carreras restantes: 8 hs reloj semanales, distribuidas en 2 clases teóricas de 2 hs reloj de duración cada una y 2 clases prácticas, también de 2 hs. reloj cada una.

La variedad de perfiles de formación que atraviesan a la asignatura, así como también el elevado número de alumnos que la cursan (ya que sus clases se dictan en el primer cuatrimestre del primer año de estudios de las ocho carreras mencionadas), obligan a trabajar en numerosas comisiones de clases tanto teóricas (3) como prácticas (11), lo cual complejiza el proceso de seguimiento y evaluación de los procesos de enseñanza y aprendizaje durante el cursado de la asignatura. Cabe señalar que el número de alumnos que cursan la asignatura (gene- 
ralmente superior a 600) está directamente afectado por los denominados recursantes es decir, aquellos estudiantes que, habiendo ingresado a la Facultad en algún año lectivo anterior, vuelven a cursar la asignatura ya sea por no haber alcanzado la condición de alumno regular en ella o por haber perdido tal condición.

El elevado número de recursantes habla del alto nivel de fracaso de los estudiantes a la hora de cursar la asignatura, fracaso vinculado no sólo con la imposibilidad de aprobar durante el cuatrimestre sus dos exámenes parciales (o en su defecto los correspondientes recuperatorios) sino también con un fuerte porcentaje de desgranamiento. Por ejemplo, en 2017 de los 621 alumnos inscriptos para cursarla, cerca del $40 \%$ no lo hizo (se considera que no cursó la asignatura aquel que, al momento de implementarse el primer parcial ya había superado el $25 \%$ de inasistencias sobre el total de clases prácticas previstas de dictarse en todo el cuatrimestre). De los 381 que sí la cursaron, el 15\% dejó de asistir a clases antes del segundo parcial es decir, sólo el 45\% de los inscriptos completó el cursado de la materia. De estos últimos, el 48\% regularizó la asignatura (sólo el $22 \%$ de los inscriptos) [1].

Por todo lo antes expuesto, en este trabajo se determinó el porcentaje de desgranamiento y se realizó un análisis estadístico descriptivo de los resultados del cursado (discriminados según las distintas comisiones de práctico) correspondientes al año lectivo 2018. A fin de determinar si la mayor carga horaria favorece o no el rendimiento académico de los alumnos, se contrastaron los resultados de las comisiones correspondientes a las Ingenierías con los de las otras carreras.

\section{DESARROLLO \\ 2.1. ALGUNAS CONSIDERA- CIONES PREVIAS}

Si bien anteriormente se describió someramente la forma en que se organizan las tareas áulicas, se describe en este apartado cuál fue la distribución de clases prácticas de los alumnos en 2018, a fin de facilitar la interpretación de los resultados obtenidos.

Los alumnos de Bioquímica, Licenciatura en Ciencias Químicas o Profesorado en Ciencias Químicas y del Ambiente (ingresantes y recursantes) fueron distribuidos en 4 comisiones: 1, 2, 3 y 7. En cambio, todos los estudiantes de Ingeniería en Agrimensura asistieron a las clases de la comisión 5 y todos los de Licenciatura y Profesorado en Física a las de la 6.

Los ingresantes y recursantes de Ingeniería Eléctrica fueron distribuidos en las comisiones 4 y 9, mientras que los de Ingeniería en Electrónica en las comisiones 8, 10 y 11.

Para regularizar la asignatura, los estudiantes deben contar con el $75 \%$ o más de asistencia a clases prácticas y aprobar (con una calificación de 6 o más puntos sobre un total de 10) dos exámenes parciales (o sus recuperatorios), referidos a los aspectos prácticos de los contenidos del programa. El orden de implementación de estas instancias de evaluación fue, en 2018, para todas las carreras el siguiente: 
1. Primer examen parcial (fines de abril). Contenidos evaluados: Lógica proposicional y de predicados, Teoría intuitiva de conjuntos, Rielaciones y funciones, Funciones reales no polinómicas de una variable real, Números complejos, Polinomios y funciones polinómicas (Trabajos prácticos 1 a 5 , inclusive).

2. Segundo examen parcial (segunda semana de junio). Contenidos evaluados: Algebra lineal. Algebra de matrices, Sistemas de ecuaciones lineales y Variedades lineales en el plano y en el espacio ( 3 trabajos prácticos).

3. Recuperatorio del Primer Parcial (tercera semana de junio).

4. Recuperatorio del Segundo Parcial (cuarta semana de junio).

5. Recuperatorio Extraordinario (Primera Semana de julio).

Independientemente de la carrera, se pueden considerar distintas categorías de alumnos entre los inscriptos para cursar la asignatura:

En principio, tenemos alumnos de la categoría NO CURSÓ (ya se explicó en el apartado anterior quiénes la constituyen) y de la categoría CURSÓ. Los individuos de esta última categoría, a su vez - en cada examen parcial o recuperatorio - pueden clasificarse en 3 grupos: Aprobados (AP), Desaprobados (D) o Ausentes (AU); al analizar por comisiones el resultado final de la cursada, también pueden distinguirse tres categorías: Regulares (los que aprobaron los dos parciales y alcanzaron el $75 \%$ o más de asistencia a clases prácticas), Libres por
Parciales (los que no aprobaron algún parcial ni su recuperatorio) y Libres por Asistencia (los que abandonaron la cursada).

\subsection{METODOLOGIA}

Para realizar el análisis de resultados académicos por comisión de clases prácticas, se utilizó Análisis de Datos Composicionales. Esta técnica, se utiliza para analizar vectores $\mathrm{n}$ - dimensionales de componentes no negativas que expresan proporciones de un total es decir, en tres dimensiones, dado el vector $(x, y, z)$ debe ser $x+y+z=1$ ó $x+$ $y+z=100$ (si los datos están expresados en porcentajes).

Así pues, para el análisis del desempeño de los estudiantes en los parciales, usaremos un vector $X=(x 1, x 2, x 3)$, donde: $x 1$ representa el porcentaje de alumnos que aprobaron el examen, $\mathrm{x} 2$ es el porcentaje de alumnos que desaprobaron el parcial y x3 denota el porcentaje de alumnos ausentes en la evaluación.

En cambio, para el análisis de los resultados finales del cursado, las componentes son vectores $Y=(y 1, y 2, y 3)$, con: $y 1$ : porcentaje de alumnos que regularizaron la asignatura, porcentaje de alumnos que quedaron libres por asistencia e y3: porcentaje de alumnos que quedaron libres por parciales.

Es usual presentar el análisis de datos composicionales mediante los denominados gráficos ternarios. Los mismos resultan pertinentes para representar vectores tridimensionales en el plano, por la validez de la propiedad de los triángulos equiláteros que afirma que las paralelas a cada lado trazadas 
por un punto $\mathrm{p}$ del triángulo, determinan sobre cada uno de dichos lados segmentos tales que la suma de sus longitudes es constante e igual a la longitud del lado [2]. Así pues, el conjunto de puntos representados en un gráfico ternario, determina un espacio denominado espacio simplex [3]. En este trabajo, se utilizaron gráficos $\mathrm{yd}$.

\section{Categoría 1}

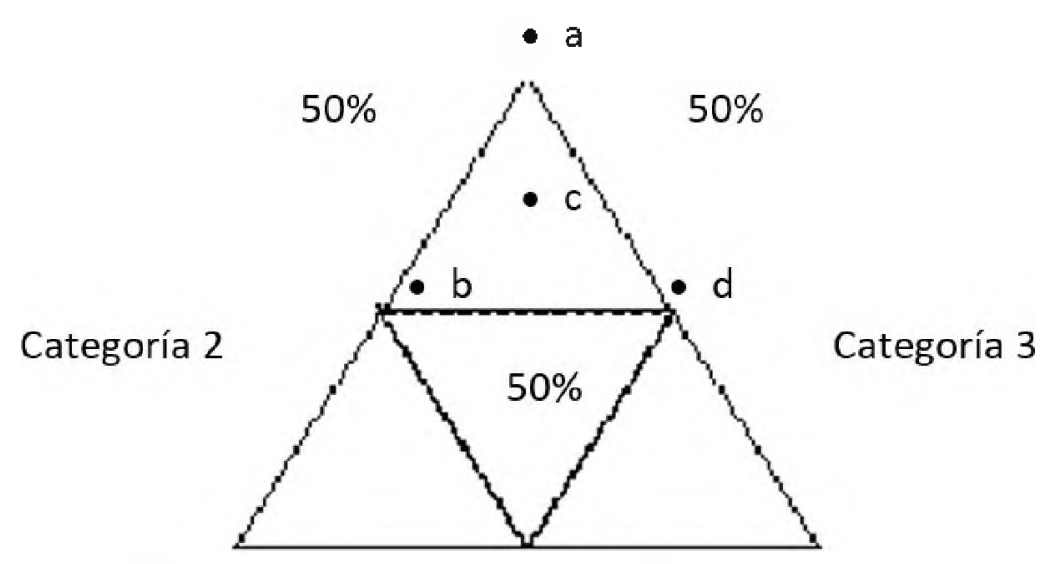

Figura 1: Interpretación de gráficos ternarios
Al aplicar este método de análisis se pueden distinguir 4 grupos:

1. Un primer grupo constituido por sujetos u objetos entre los que predomina la Categoría 1, representados por puntos en el triángulo superior, como por ejemplo el representado por el punto a.

2. Otro formado por sujetos u objetos entre los que predomina la Categoría 2, representados por los puntos en el triángulo izquierdo, como por ejemplo el representado por el punto $b$.

3. Un tercero conformado por sujetos u objetos para los que los porcentajes son ternarios en los que las escalas de las componentes están orientadas de menor a mayor (0\% a 100\%) en el sentido de las agujas del reloj.

A modo de ejemplo, presentamos un gráfico ternario y explicaremos el significado que puede asignarse a los puntos a, b, c 
desempeño de los alumnos en el cursado de la asignatura en las distintas comisiones durante 2018 se graficaron las cápsulas convexas de las comisiones correspondientes a alumnos de Ingeniería y las de las comisiones de alumnos de otras carreras.

\subsection{RESULTADOS}

A fin de explorar los porcentajes de desgranamiento sufridos durante el cursado de la asignatura se ha considerado que los alumnos en tal situación son aquellos que no cursaron ( $25 \%$ o más de inasistencias a clases prácticas antes del primer examen parcial) y los que quedaron libres por asistencia es decir, los que abandonaron el cursado de la asignatura habiendo asistido regularmente hasta el primer parcial. Así pues, en la Tabla 1 puede observarse que de los 647 alumnos inscriptos para cursarla, sólo el $68 \%$ la cursó y sólo el 49\% completó el cursado.

Tabla 1: Desgranamiento en el año lectivo 2018

\begin{tabular}{|c|c|c|c|c|c|c|}
\hline $\begin{array}{c}\text { Número } \\
\text { de }\end{array}$ & \multicolumn{2}{|c|}{$\begin{array}{c}\text { No } \\
\text { Cursaron }\end{array}$} & \multicolumn{2}{c|}{$\begin{array}{c}\text { Libres por } \\
\text { Asistencia }\end{array}$} & \multicolumn{2}{c|}{ Desgranamiento } \\
\cline { 2 - 7 } Inscriptos & $\mathbf{N}^{\mathbf{0}}$ & $\mathbf{\%}$ & $\mathbf{N}^{\mathbf{0}}$ & $\mathbf{\%}$ & $\mathbf{N}^{\mathbf{0}}$ & $\%$ \\
\hline 647 & 207 & 32 & 122 & 19 & 329 & 51 \\
\hline
\end{tabular}

En particular, de los 376 estudiantes de las carreras de Ingeniería inscriptos en 2018, un 30\% no cursó la asignatura y un 18\% abandonó el cursado. Así pues, en el caso de estas carreras el desgranamiento es cercano al $48 \%$ de los inscriptos.

Por otra parte, consultando el Informe de la cátedra correspondiente al año 2017 [1], se observa que 482 estudiantes inscriptos no regularizaron la asignatura en dicho año lectivo (sea porque no cursaron, no cumplieron con el $75 \%$ de asistencia a clases prácticas o no lograron aprobar los exámenes parciales). De los mismos, sólo el 30.5\% (147 alumnos) se inscribió en 2018 para recursarla, lo cual muestra que el des- granamiento se produce no sólo durante el cursado de la asignatura si no, también, año a año.

Cabe señalar, también, que de estos 147 recursantes cerca de un 20\% (29 alumnos) no cursó la asignatura, a pesar de haberse inscripto para hacerlo, y un 11\% (17 estudiantes) volvió a quedar libre por no alcanzar el 75\% de asistencia a las clases prácticas.

Para analizar el rendimiento académico por parciales y por comisión de clases prácticas del año lectivo 2018, se considerarán los alumnos que cursaron la asignatura (aunque hayan abandonado el cursado en algún momento) es decir, que la población 
en estudio es de 440 estudiantes.

En la Figura 2 se puede observar que en la mayoría de las comisiones, con excepción de la 5 y 9, el número de alumnos desaprobados supera holgadamente el 50\%, registrándose pocas inasistencias (sólo el 7.5\% de los estudiantes en condiciones estuvo ausente en dicha oportunidad).

La comisión 5 (correspondiente a Ingeniería en Agrimensura) es la que registra mayor número de aprobados (23) que de desaprobados (20) y es la razón por la cual el punto correspondiente se ubica en el triángulo central del gráfico ternario, más cerca del vértice AP. En la comisión 9 (formada por alumnos de Ingeniería Eléctrica, aunque no por todos ellos), los números de estudiantes aprobados y de desaprobados son iguales, pero no llegan a constituirse en el 50\% pues se registró 1 inasistencia. Esto explica su proximidad al punto medio del lado del triángulo de extremos AP (aprobados) y D (desaprobados).

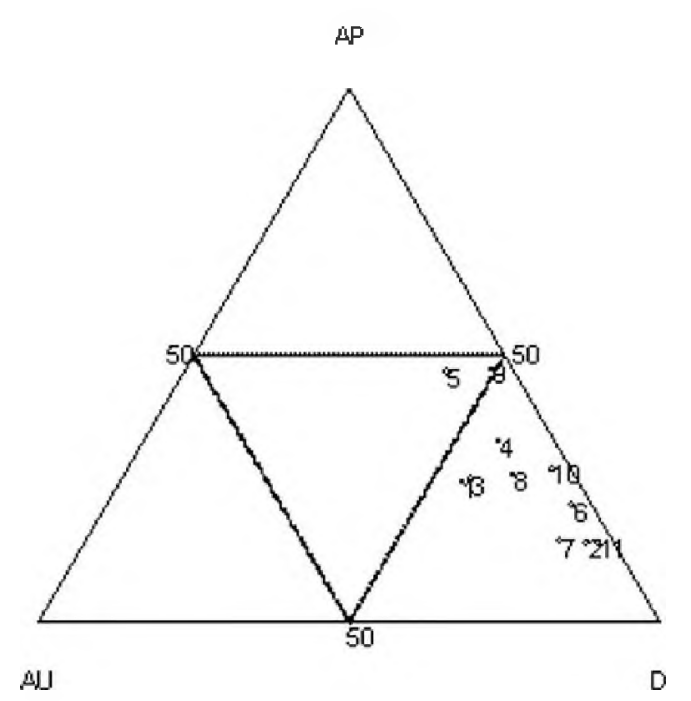

Figura 2: Resultados del primer parcial discriminados

por comisión de clases prácticas

Al analizar los resultados del segundo parcial y de los recuperatorios, puede observarse que el número de alumnos ausentes crece considerablemente como consecuencia de que, al ser casi al final del cuatrimestre, hay un alto porcentaje de alumnos que ya han quedado libres por inasistencias (al momento de rendir el segundo parcial, 92 alumnos ya habían quedado libres por esta causa). En efecto, al analizar los resultados del segundo parcial, se observa que el porcentaje total de alumnos ausentes es ya del $27 \%$.

Vemos en la Figura 3 que en las comisiones 3, 4, 5, 7 y 9 vuelven a predominar los alumnos desaprobados, mientras que en las 
restantes los porcentajes de cada categoría ble el primer parcial, que el segundo, mienson similares. Sin dudas, a los alumnos de tras que en las comisiones restantes ocurrió las comisiones 5 y 9 les resultó más accesi- todo lo contrario.

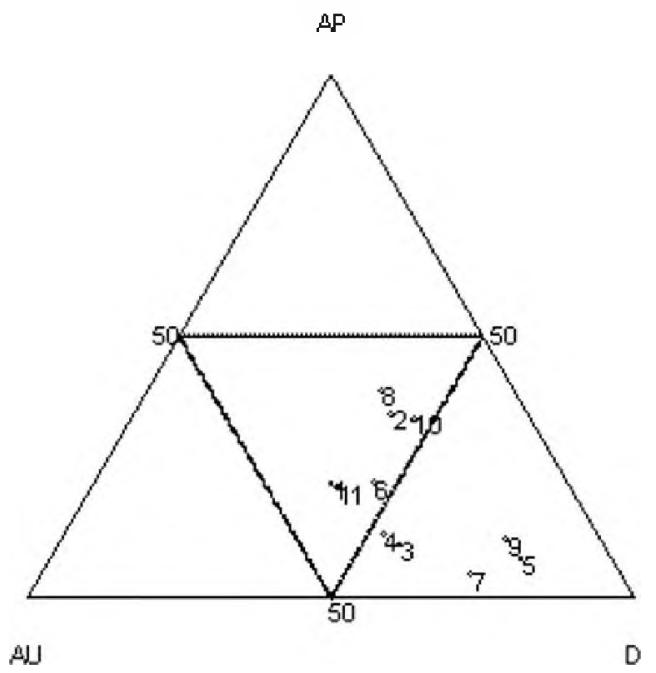

Figura 3: Resultados del segundo parcial discriminados por comisión de clases prácticas

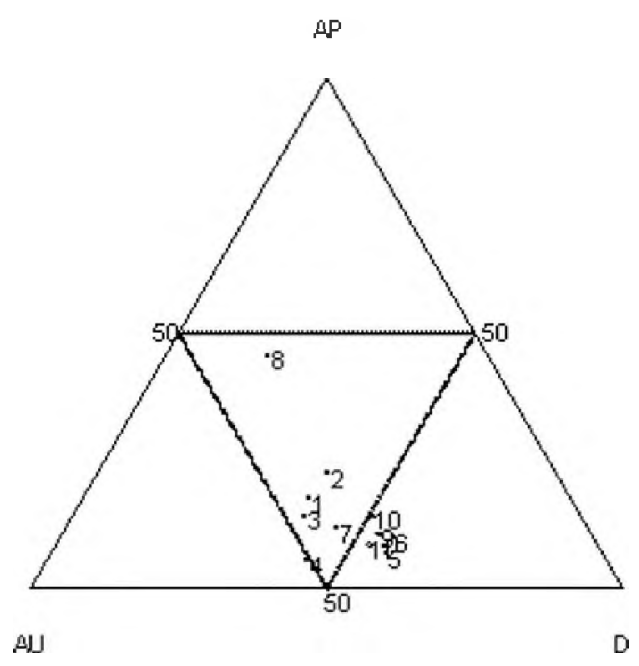

Figura 4: Resultados del recuperatorio del primer parcial según comisión de práctico

Cabe señalar que sólo el 68\% de los parcial rindieron su recuperatorio. Puede alumnos que habían desaprobado el primer observarse en la Figura 4 que en las comi- 
siones 5, 6, 10 y 11 vuelven a predominar los alumnos desaprobados, mientras que en las demás los tres porcentajes son similares. La comisión 8 es la que en esta instancia tuvo el mayor porcentaje de aprobados (47\%). También puede mencionarse el hecho que, mientras en el primer parcial la comisión 5 obtuvo un alto porcentaje de alumnos aprobados, en la instancia de recuperación resultó todo lo contrario: sólo el $12.5 \%$ de los alumnos que rindieron este examen lo aprobó (mientras que en el parcial lo había aprobado el $53 \%$ de los estudiantes que lo rindieron). Algo similar sucede con la comisión 9: mientras que el $50 \%$ de los que rindieron el primer parcial lo aprobó, el recuperatorio sólo fue aprobado por el 18\% de los presentes.

De la misma manera, al recuperatorio del segundo parcial asistió sólo el 74\% de los que habían desaprobado dicho examen. Dado que entre las dos instancias de evaluación transcurrieron sólo 14 días (período en el cual se dictó sólo una clase práctica), puede concluirse que ese $26 \%$ de alumnos estuvo voluntariamente ausente, pues no parece probable que todos ellos perdieran la regularidad por inasistencias en dicho momento.

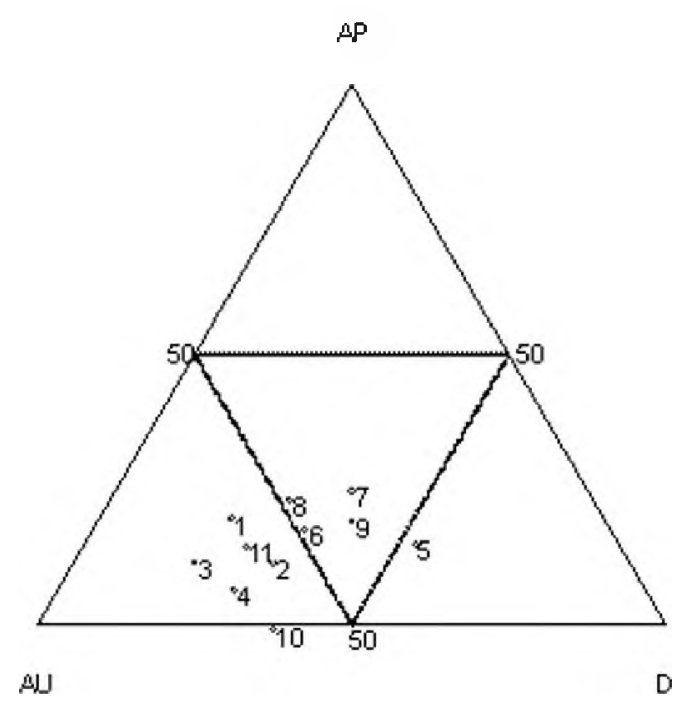

Figura 5: Resultados del recuperatorio del segundo parcial según comisión de práctico

Se observa en la Figura 5 que, nuevamente, la comisión 5 tiene un elevado porcentaje de alumnos desaprobados (77\%) de los asistentes. La comisión 10 (formada exclusivamente por alumnos ingresantes a Ingeniería en Electrónica), en cambio, no registró alumnos aprobados pero sí un $62.5 \%$ de alumnos ausentes (de allí que el punto que la representa se ubica sobre el lado de extremos AU y D, a 
1a izquierda del 50\%). En las comisiones en las comisiones restantes los porcenta$1,2,3,4$ y 11 , se registraron altos porcen- jes correspondientes a cada categoría son tajes de alumnos ausentes, mientras que similares.

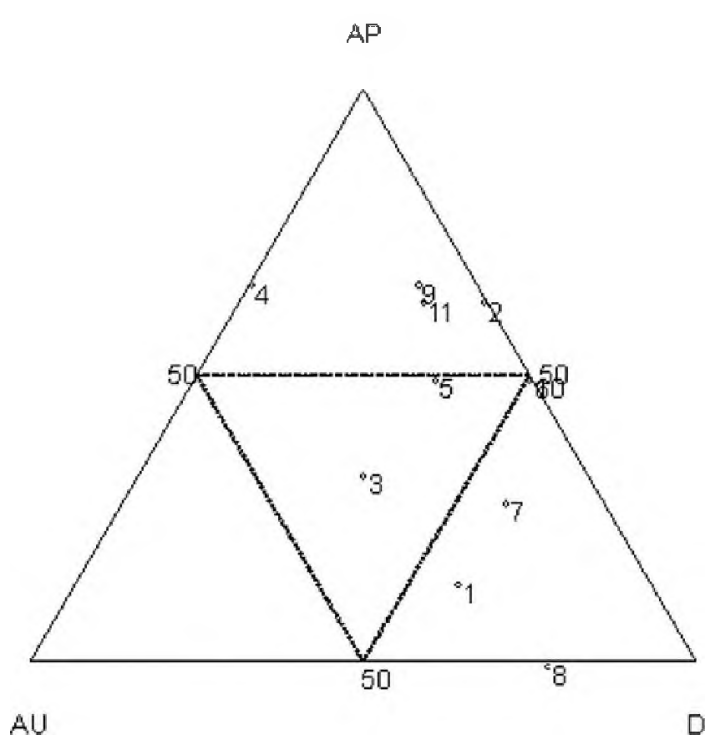

Figura 6: Resultados del recuperatorio extraordinario según comisión de práctico

En la Figura 6 puede verse que los mayores porcentajes de aprobados corresponden a las comisiones $2,4,9$ y 11 . Mientras que en las comisiones 1 y 7 predominan los desaprobados. En la comisión 10 no se registraron inasistencias y aprobó el $50 \%$ de los alumnos que rindieron el recuperatorio. Se observa que las comisiones 3 y 5 presentan porcentajes similares en las tres categorías, mientras que en las comisiones 1 y 7 predominan los desaprobados.

En cuanto a los resultados obtenidos en el recuperatorio extraordinario, se pudo observar un mayor número de alumnos ausentes entre los que debían rendir el segundo parcial. Además, el 50\% de los alumnos en condiciones de rendir el primer parcial lo aprobaron. Mientras que en el segundo parcial el $46 \%$ de los alumnos en condiciones de rendir fue aprobado. Estos porcentajes se elevan a 53\% y $56 \%$, respectivamente, si sólo se consideran los alumnos que efectivamente rindieron.

Las comisiones 3 , 4 y 5 no contaban con alumnos en condiciones para recuperar el primer parcial. Se observa que en las comisiones 2 y 11 hay mayor número de alumnos a recuperar el primer parcial (8), y que además son los que presentan mayor cantidad de alumnos aprobados (6). Los dos alumnos de la comisión 9 en condiciones de recuperar el primer parcial aprobaron. 


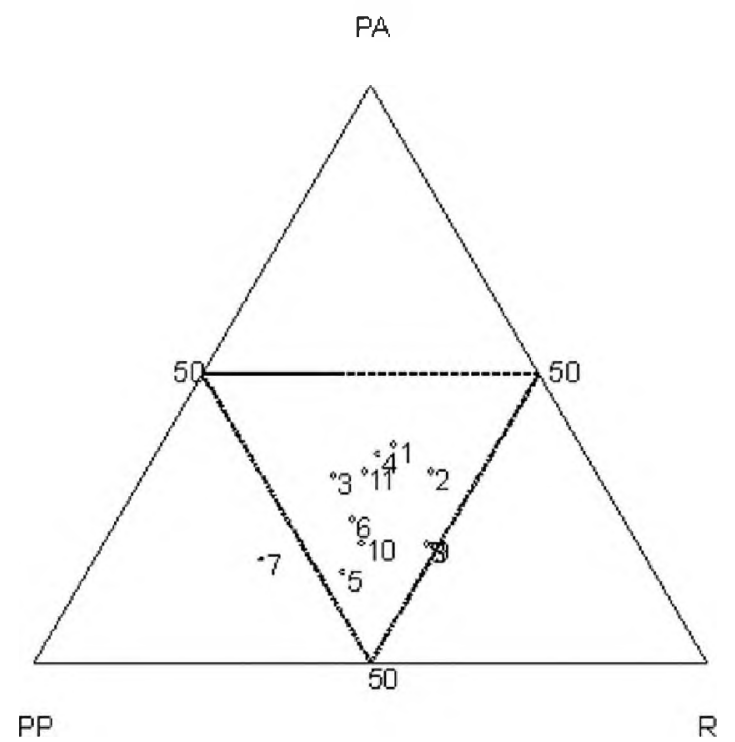

Figura 7: Resultados finales del cursado del año lectivo 2018

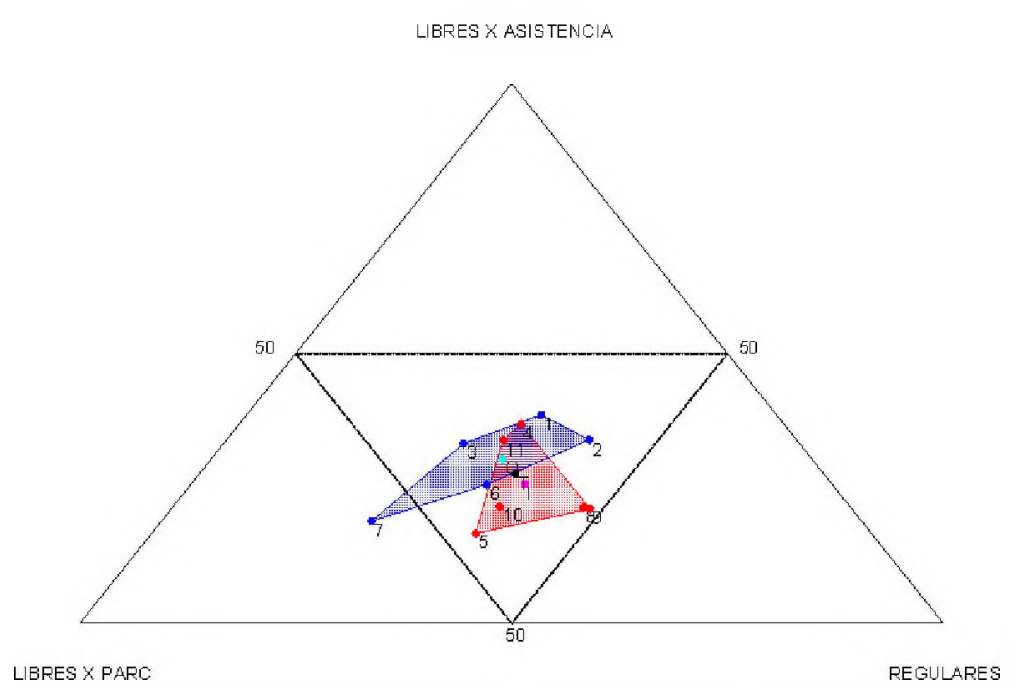

LIBRES $X$ PARO

REGULARES

Carreras de Ingeniería Otras carreras

Figura 8: Resultados del cursado según tipo de carreras

Se observa aquí (Figura 7) que, salvo les (PP) son aproximadamente los mismos. la comisión 7, en diez comisiones los por- En la comisión 7 (correspondiente a Biocentajes de alumnos regulares ( $\mathrm{R}$ ), de libres química), en cambio, predominan los libres por asistencia (PA) y de libres por parcia- por parciales (57\%) por sobre los regulares 
(24\%) y por los libres por asistencia (19\%). Cabe señalar que de aquellos alumnos que completaron el cursado de la asignatura (318), casi el 51\% la regularizó.

Finalmente, puede observarse que las comisiones de alumnos de Ingeniería tuvieron un desempeño ligeramente mejor que el resto de las comisiones de otras carreras ya que la envolvente convexa correspondiente a Ingeniería (señalada con rojo) está ubicada más cerca del vértice de regulares. (Figura 8)

\section{CONCLUSIONES}

A partir de los resultados obtenidos, puede concluirse que el bajo rendimiento académico de los alumnos de Algebra y Geometría Analítica se explica, principalmente, por el desgranamiento de los alumnos durante el cuatrimestre en que la cursan. En efecto, se ha visto que en 2017 y en 2018, casi la mitad de los estudiantes que completaron el cursado de la asignatura, la regularizaron (48 y 50.6\%, respectivamente), porcentajes que si bien no son muy altos, son mejores que los obtenidos en muchas asignaturas de estas carreras correspondientes a años superiores del plan de estudios.

Esta problemática del desgranamiento obedece, sin dudas, a diversas causas entre las cuales puede citarse la insuficiencia de contenidos procedimentales propios de la Matemática que son imprescindibles para la validación de los saberes matemáticos en el Nivel Superior (deficiencia que se aprecia en el desempeño de los estudiantes en los exámenes parciales) y que obedecen a que en la formación preuniversitaria no han alcanzado la evolución del pensamiento aritmético al algebraico. Así pues, ante la complejidad y el nivel de abstracción requeridos por los objetos matemáticos en estudio, los estudiantes abandonan el curso pues les es muy difícil relacionar desde la lógica disciplinar los distintos contenidos incluidos en el programa de la asignatura, los cuales resultan excesivos para ser abordados didácticamente, desde la formalidad y rigor que requiere la enseñanza y el aprendizaje en el Nivel Universitario, en tan sólo cuatro meses.

En el caso particular de las tres carreras Ingeniería (donde se ha visto que el desgranamiento alcanzó el $48 \%$ de los alumnos inscriptos), además de la causa antes mencionada, pueden considerarse factores curriculares tales como, por un lado que dichos alumnos cursan en forma simultánea cuatro asignaturas (Algebra y Geometría Analítica, Cálculo Diferencia e Integral I, Química General y el Módulo I del Seminario de Ingeniería) que les exige mucha carga horaria presencial, atentando contra la posibilidad del aprendizaje autónomo por parte de los estudiantes. Además, como para cursar las asignaturas correspondientes al segundo cuatrimestre del primer año no se requiere haber regularizado Algebra y Geometría Analítica, los alumnos priorizan regularizar aquellas asignaturas que, de no ser regularizadas, les impiden avanzar en sus estudios el resto del año.

Para paliar este grave problema, podrían plantearse algunas propuestas superadoras: una sería modificar la duración de 
la asignatura, convirtiéndola en anual, en vez de cuatrimestral; otra, dictar sus clases en el segundo cuatrimestre de primer año o en el primero del segundo año de estudios (dos momentos en los cuales los alumnos ya han transitado parte del proceso de socialización en la Institución); una tercera es dividir la asignatura en dos: una correspondiente al primer cuatrimestre que incluya sólo contenidos de Algebra y de Matemática Discreta y otra, en el segundo cuatrimestre centrada en Algebra Lineal y Geometría Analítica; por último podría introducirse como requisito para el cursado de Cálculo Diferencial e Integral II su regularización lo cual - desde una perspectiva epistemológica - parece la más adecuada, puesto que para el aprendizaje de funciones reales de dos variables reales es necesario un conocimiento sólido respecto a cónicas y cuádricas. Sin embargo, es evidente que todas estas posibles soluciones traen implícito cambios en los planes de estudios, facultad que no es inherente a los Profesores Responsables de cátedras.

Respecto a qué examen parcial representa un mayor obstáculo para la regularización de la asignatura, no puede concluirse nada por las fluctuaciones de los números de aprobados y desaprobados en las distintas comisiones. Sí podría concluirse que para los alumnos de Ingeniería en Agrimensura los contenidos evaluados en el primer parcial resultan más accesibles que los incluidos en el segundo, tal vez porque dichos saberes pueden abordarse con un pensamiento más cercano al aritmético que al algebraico.
Finalmente, se concluye que una mayor carga horaria presencial de clases prácticas favorece el rendimiento académico de los alumnos, como se demuestra mediante el hecho de que los estudiantes de las carreras de Ingeniería tuvieron un mejor desempeño que el de las otras carreras.

\section{REFERENCIAS BIBLIOGRÁFICAS}

[1] Caputo, L. (2017). Informe Final de la cátedra "Algebra y Geometría Analítica". FACENA. UNNE.

[2] Aitchison, J. (1986). The Statistical Analysis of Compositional Data. Editorial Chapman \& Hall LTD. Londres, Gran Bretaña. 416 pp.

[3] Simeray, J.P. (1979): Los Gráficos al Servicio de la Empresa. Eds: Deusto S.A. Bilbao, España. 461 pp.

[4] Preparata, F.P.; Hong, S.J. (1977). Convex Hulls of Finite Sets of Points in Two and Three Dimensions. Asociation for Computing Machinery. 87-93 pp. Disponible en: https://www.cs.jhu.edu/ misha/Spring16/ Preparata77.pdf. Ultima fecha de acceso: 28 de noviembre de 2018. 